\title{
Diarrhea in Farmed White-tailed Deer Fawns ${ }^{1}$
}

\author{
Juan M. Campos Krauer and Samantha M. Wisely ${ }^{2}$
}

\section{Introduction}

Diarrheal diseases, commonly called scour, are common in newborn ruminant farm animals including deer fawns. The clinical presentation can range from mild diarrhea without systemic disease to profuse, acute diarrhea associated with rapid dehydration and death, sometimes within hours of onset. Although a number of different viruses can cause diarrheal disease in young fawns, bacteria in the group Enterobacteriaceae are important contributors. These bacteria are sometimes called enteropathogens. They live in the intestinal tract of animals, including humans. Some of them are part of the normal flora of bacteria, and others can cause disease and diarrhea under certain conditions. Enterobacteria that can cause diarrheal disease in deer fawns include Escherichia coli, Clostridium perfringens, and Salmonella sp. Determining the particular agents associated with an outbreak of diarrhea is important for assigning appropriate prophylaxis and therapy. However, in this fact sheet, we will focus on disease in fawns caused by pathogenic types of Escherichia coli.

\section{What is Escherichia coli?}

Escherichia coli is a Gram-negative, rod-shaped facultative anaerobic bacterium, which belongs to the Enterobacteriaceae family (Figure 1). It colonizes the gastrointestinal tract within the first hours of life and is one of several types of bacteria that normally inhabit the lower intestine of humans, mammals, and birds (Gyles et al. 2004). Most strains of the bacterium are harmless, but some strains of $E$. coli are capable of causing opportunistic infections. A few strains are of high pathogenicity and cause a variety of intestinal, septicemic and extra-intestinal diseases (Quinn et al. 2011). Disease caused by pathogenic E. coli generally affects fawns during the first days of life, but systemic infection can occur in young deer up to one year, and less often in adult animals (Arthur et al. 2004).

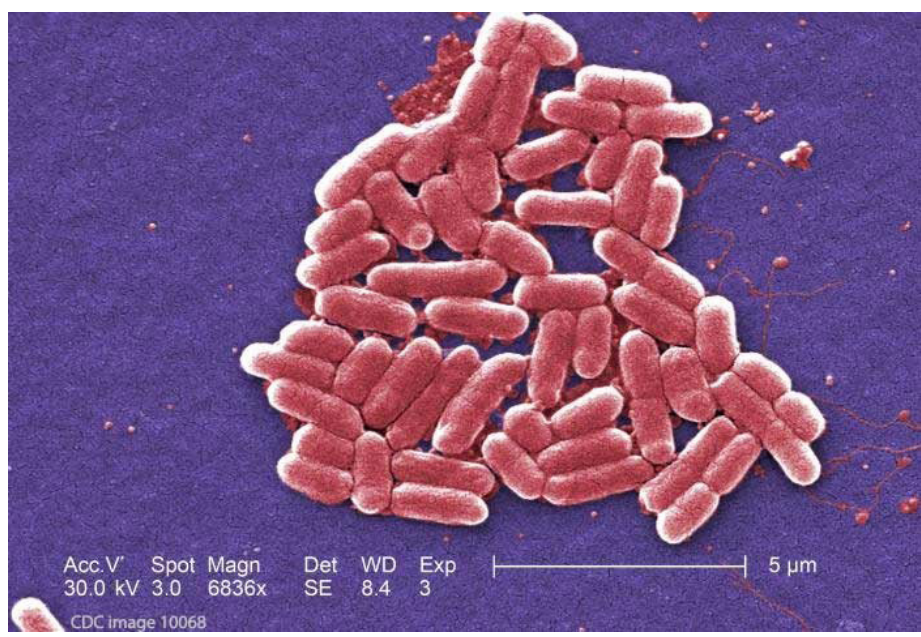

Figure 1. Electron micrograph image of a number of Gram-negative Escherichia coli bacteria of the strain 0157:H7, which is one of hundreds of strains of this bacterium.

Credits: Janice Haney Carr (PHIL CDC image ID\# 10068)

1. This document is WEC418, one of a series of the Department of Wildlife Ecology and Conservation, UF/IFAS Extension. Original publication date January 2020. Visit the EDIS website at https://edis.ifas.ufl.edu for the currently supported version of this publication.

2. Juan M. Campos Krauer, assistant professor, Department of Large Animal Clinical Sciences, UF College of Veterinary Medicine and Department of Wildlife Ecology and Conservation; and Samantha M. Wisely, professor, Department of Wildlife Ecology and Conservation; UF/IFAS Extension, Gainesville, FL 32611.

The Institute of Food and Agricultural Sciences (IFAS) is an Equal Opportunity Institution authorized to provide research, educational information and other services

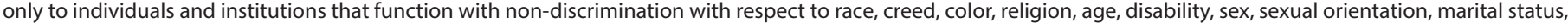

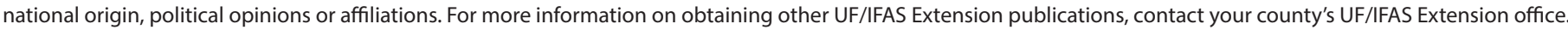
U.S. Department of Agriculture, UF/IFAS Extension Service, University of Florida, IFAS, Florida A \& M University Cooperative Extension Program, and Boards of County Commissioners Cooperating. Nick T. Place, dean for UF/IFAS Extension. 


\section{How do fawns get infected with $E$. coli?}

While most E. coli are harmless and are naturally present in the small intestine, concentrations of the organism increase progressively towards the large intestine. E. coli is shed with feces and can survive for weeks and months in fecal particles and dust (Gyles et al. 2004). It is assumed that the primary source of pathogenic E. coli infection in fawns is ingestion of feces from infected animals. Carriers of pathogenic strains may look completely healthy but serve as a source of disease to young animals. When newborn animals develop clinical diarrheic disease, they serve as multipliers of the organisms, contributing to the spread of the infection to other animals in the herd (Quinn et al. 2011).

Some factors can predispose fawns to pathogenic E. coli infections and development of diarrheal disease. These include a deficiency of circulating antibodies as the result of a failure in passive transfer of colostral immunoglobulin, stress due to poor management or bad weather, overcrowding, accumulation of undigested foods in young animals, infected open wounds (navel), broken skin, or by direct nose-to-nose contact or exposure to urinary and respiratory aerosols (Mackintosh et al. 2002, Quinn et al. 2011). However, one of the most important factors is poor hygiene in the pen and enclosures with the accumulation of large amounts of feces.

\section{What are the symptoms of infection from $E$. coli?}

Deer are extremely good at hiding signs of illness. Therefore, it is imperative to detect subtle but unusual behavior and symptoms before the disease progresses. The symptoms listed below are not unique to $E$. coli but may indicate to caretakers that an animal is ill. Detection of sick animals early in the course of disease allows time for diagnostic evaluation and prompt treatment. General signs of illness, which may include E. coli infection, are summarized below (Gyles et al. 2010, Quinn et al. 2011, Aiello and Moses 2016).

- Lethargy (low energy) or weakness

- Decreased appetite

- Cloudy eyes

- Hair standing up with a rough appearance or a dull coat

- If pinched up, the skin tents and does not regain shape (sign of dehydration).
- Tachycardia, a weak rapid pulse

- Fever is not prominent, and the rectal temperature may even be below normal.

- The feces are loose and mucoid; diarrhea may be severe and watery or pasty white/yellow and foul smelling.

- Tremor, hyperesthesia (abnormal increase in sensitivity to stimuli) and convulsions are seen occasionally, but stupor and coma are more common in advanced stages.

- Death

\section{How do I know that $E$. coli is affecting my herd?}

A definite etiologic diagnosis for diarrhea based solely on clinical findings is impossible. However, the history, age of the animal and clinical signs may suggest to your veterinarian to provide a presumptive diagnosis. Fecal samples can be submitted to a veterinarian diagnostic lab, but interpretation of fecal microorganisms can be difficult because mixed infections are common. Nonpathogenic enteropathogens are commonly present in the feces of healthy fawns, which also complicates the diagnosis (Delgado et al. 2017). The best diagnostic information is usually obtained by submitting untreated, acutely affected animals for necropsy to your local veterinarian. This allows examination of intestinal mucosa for evidence of diagnostic lesions. The diagnostic value of a necropsy diminishes quickly with time after death because important lesions can disappear within minutes due to autolysis (the breakdown of animal tissue by the action of enzymes contained in the tissue; self-digestion). However, necropsy results can significantly help deer farmers take fast action to effectively treat and prevent the disease.

\section{Can $E$. coli be treated?}

Pathogenic E. coli infections can be treated, and animals that receive early treatment have a high expectation of survival. The nature and duration of therapeutic measures are determined by the severity and duration of the disease process. Generally, the principles of pathophysiology and treatment apply to most newborn herbivore species (Aiello and Moses 2016), pathophysiology being a convergence of pathology with physiology. Pathology is the medical discipline that describes conditions typically observed during a disease state, whereas physiology is the biological discipline that describes processes or mechanisms operating within an organism. Pathology describes the abnormal or undesired condition, whereas pathophysiology seeks to explain the functional changes that are occurring within an individual due to a disease or pathologic state. 
Treatment of pathogenic E. coli infections requires fluid and electrolyte therapy, aggressive use of antibiotics and antiinflammatory therapy as soon as possible (Aiello and Moses 2016). The correct use of antibiotics is extremely important to prevent bacterial resistance. E coli is increasingly becoming resistant to ampicillin, neomycin, kanamycin, spectinomycin, and tetracycline (DACA 2006). Fawns have large energy requirements and very little energy reserves, which makes them extremely vulnerable if actions are not taken quickly. Always contact your veterinarian as soon as possible for the best treatment options.

\section{Can pathogenic E. coli be prevented in your herd?}

Minimize exposure to pathogenic E. coli by isolating clinically ill animals from healthy ones. Rear fawns in a warm, clean environment and if possible separate them from the rest of the farm operations to minimize exposure and prevent infection. Practice good general hygiene, with a deep cleaning and disinfection of any contaminated fawn pens or rearing rooms. Disinfect the umbilicus or navel of the fawn at birth. Tincture of iodine with at least $7 \%$ iodine (7\% iodine, potassium iodine 5\%, isopropyl alcohol $85 \%$, and water) is an excellent antiseptic and disinfectant to prevent a navel infection with $E$. coli that can easily become a major life-threatening systemic infection. The scientific literature on the most common bacteria causing umbilical infections in animals is very limited; however, Streptococcus organisms and E. coli are the primary pathogens that cause umbilical infections in infants. These data suggest that bacteria normally present in feces can significantly contribute to the risk of umbilical infections (Mullany et al. 2003).

Currently the most effective ways of preventing pathogenic E. coli from affecting fawns is through the consumption of sufficient colostrum before the first 12 hours of birth. Colostrum is the first form of milk produced by the mammary glands of mammals immediately following delivery of the newborn and contains antibodies to protect the newborn against disease (Gyles et al. 2010, Aiello and Moses 2016). Colostrum provides essential concentrations of immunoglobulin, providing fawns with resistance to $E$. coli septicemia and other diseases (Myers 1978).

It is extremely important to ensure that fawns take plenty of colostrum in the first hours after they are born. Taking steps to minimize stress to does near the time of parturition-for instance, refraining from moving pregnant does to a new herd and ensuring that their pens are clean and quiet-may improve their fawns' uptake of colostrum. Similarly, it is very important to incorporate a management procedure that detects fawns that are not taking

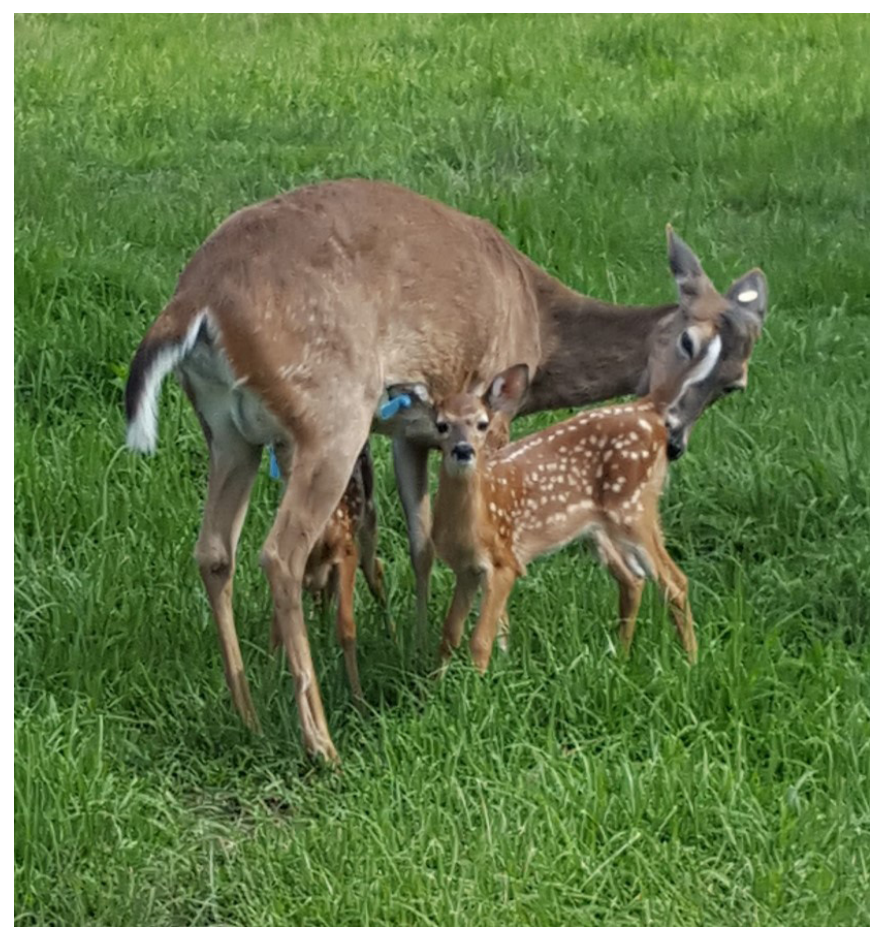

Figure 2. Twin healthy white-tailed deer fawns with their mother. Licking is important not just to keep fawns clean, but to stimulate them to defecate and urinate.

Credits: UF/IFAS, Cervidae Health Research Imitative image

colostrum and take corrective measures within the first 12 hours after birth. After 36 hours, absorption of these very important proteins is negligible in other herbivore species (Myers 1978, Meyers et al. 1973, Yanaka et al. 2012). When natural colostrum is not available for a newborn fawn, commercial colostrum substitutes, generally composed of bovine colostrum, can provide immunoglobulin for protection against $E$. coli septicemia. Again, colostrum must be fed early in the absorptive period (i.e., within 12 hours of birth) (Gyles et al. 2010). It also may be appropriate to give fawns a commercially available colostrum paste supplement specifically formulated for the unique needs of newborn fawns. It combines bovine colostrum with essential vitamins, minerals, and probiotics to deliver immune and nutritional support (Aiello and Moses 2016). Always consult your veterinarian for professional advice on colostrum, commercial colostrum supplement, or milk substitutes according to your farm needs.

Similarly, in other ruminant species, E. coli bacterin vaccines (a suspension of killed or attenuated bacteria for use as a vaccine) are commonly used in pregnant animals as a way to promote and increase antibodies in the colostrum to protect the newborn against pathogenic strains of $E$. coli. It has proven effective in cattle and goats (Myers 1978, Yanaka et al. 2012). These products have been developed for use in species other than deer, and their effectiveness in deer has not yet been fully demonstrated. 


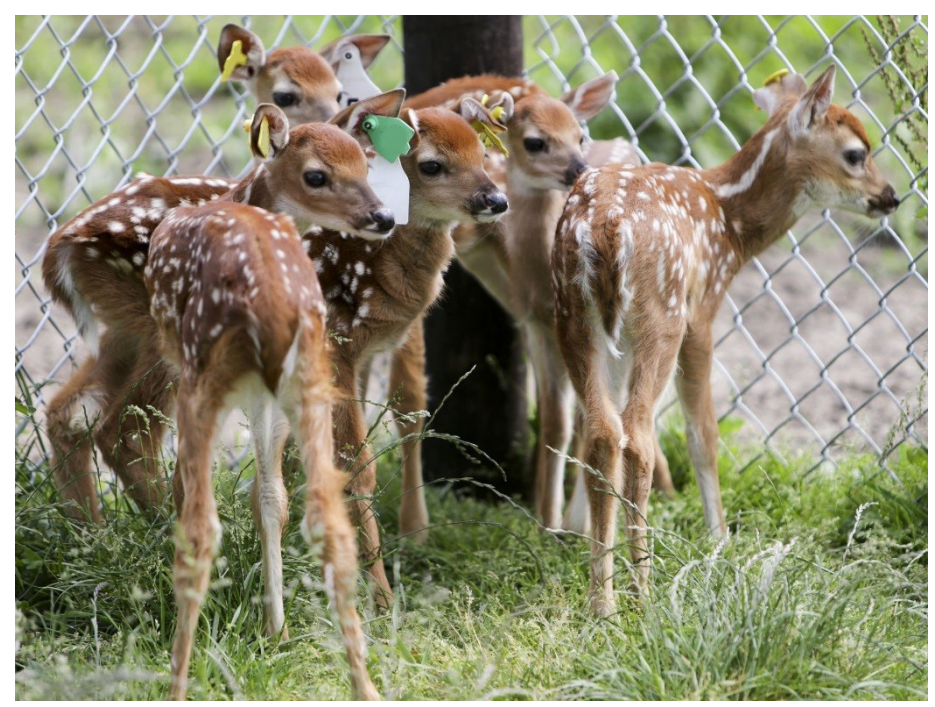

Figure 3. Group of healthy white-tailed deer fawns.

Credits: UF/IFAS, Cervidae Health Research Imitative image

Because of the complexity of diarrheal diseases in newborn and young fawns, it is unrealistic to expect total prevention. The objectives are to reduce the clinical disease, to minimize the level of exposure to infectious agents, and to increase resistance in the fawns.

It is impossible to recommend one management strategy to all deer farms because they will greatly vary according to differences in land and herd size, pen numbers and size, availability of facilities, labor, and general production objectives. However, some principles can be applied to all farms.

- Good general hygiene is fundamental to reduce disease exposure in fawns.

- If you have a diseased animal, isolate that animal in a separate area until it has recovered.

- Good nutrition and management of does is critical to promote the production of high-quality colostrum.

- Newborn fawns need to consume plenty of colostrum during the first hours after birth. A significant number of fawns do not acquire adequate amounts of immunoglobulin because of delayed sucking or feeding, inadequate volume of colostrum, or ingestion of colostrum with inferior immunoglobulin concentration.

- Monoclonal E. coli antibodies (ecolizers) are available commercially for oral administration to fawns immediately after birth. However, their use will depend on the type of farm and management you have.

\section{Personal Protection}

Many of the agents that produce diarrhea in fawns and young deer can also produce diarrheal disease in humans (Chapman and Ackroyd 1997, Delgado et al. 2017). To prevent any possible infection, wash and disinfect your hands after handling deer. Hand cleaning and disinfection should be a daily practice in all deer farms.

\section{References}

Aiello, S. E., and M. A. Moses. 2016. "Colisepticemia." The Merk Veterinary Manual. 11th Edition. Kenilworth. Merck \& CO., INC. NJ, USA. P. 749-750

Aiello, S. E., and M. A. Moses. 2016. "Diarrhea in Neonatal Ruminants." The Merk Veterinary Manual. 11th Edition. Kenilworth. Merck \& CO., INC. NJ, USA. P. 275-280

Hattel, Arthur L., Daniel P. Shaw, Brenda C. Love, Donald C. Wagner, Thomas R. Drake, and Jason W. Brooks. 2004. "A Retrospective Study of Mortality in Pennsylvania Captive White-Tailed Deer (Odocoileus virginianus): 2000-2003." J Vet Diagn Invest 16: 515-521 https://doi. org/10.1177/104063870401600605 PMid:15586566

Chapman, P. A., and H. J. Ackroyd. 1997. "Farmed Deer as a Potential Source of Verocytotoxin-Producing Escherichia coli O157." The Veterinary Record 141: 314-315. PMid:9330481

CHeRI. University of Florida Cervidae Health Research Initiative. https://wec.ifas.ufl.edu/cheri/

DACA. 2006. "Colisepticemia." Standard Treatment Guidelines for Veterinary Practice. First Edition. Drug administration and control authority of Ethiopia, Addis Ababa, Ethiopia: P 46

Delgado, M. L., P. Singh, J. F. Funk, J. A. Moore, E. M. Cannell, J. Kanesfsky, S. D. Manning, and K. T. Scribner. 2017. "Intestinal Microbial Community Dynamics of WhiteTailed Deer (Odocoileus virginianus) in an Agroecosystem." Microb Ecol Aug 74(2): 496-506. https://doi.org/10.1007/ s00248-017-0961-7 PMid:28293696

Gavier-Widen, Dolores, J. Paul Duff, and Anna Meredith. 2012. "Escherichia Infections." Infectious Diseases of Wild Mammals and Birds in Europe. Blackwell Publishing Ltd. Oxford UK. 381-385

Gyles, C. L., J. F. Prescott, J. G. Songer, and C. O. Thoen. 2010. "Escherichia coli"Pathogenesis of Bacterial Infections in Animals. 4th Edition. Blackwell Publishing Ltd. Ames, Iowa, USA. 267-309 https://doi.org/10.1002/9780470958209.ch15 
Quinn, P. J., B. K. Markey, F. C. Leonard, E. S. Fitzpatrick, S. Fenning, and P. J. Hartigan. 2011. "Enterobacteriaceae." Veterinary Microbiology and Microbial Disease. Blackwell Publishing Ltd. Oxford UK. 263-273

Mackintosh, C., J. C. Haigh, F. Griggin. 2002. "Bacterial Diseases of Farmed Deer and Bison." Revue scientifique et technique (International Office of Epizootics). 21: 249-63. https://doi.org/10.20506/rst.21.2.1341

Mullany, L. C., G. L. Darmstadt, and J. M. Tielsch. 2003. "Role of Antimicrobial Applications to the Umbilical Cord in Neonates to Prevent Bacterial Colonization and Infection: A Review of the Evidence." Pediatr. Infect. Dis. J. 22:996-1002. https://doi. org/10.1097/01.inf.0000095429.97172.48 PMid:14614373 PMCid:PMC1317298

Myers, L. L. 1978. "Enteric Colibacillosis on Calves: Immunogenicity and Antigenicity of Escherichia coli antigens." Am. J. Vet. Res. 39:761-765.

Myers, L. L., F. S. Newman, R. A. Wilson, and J. E. Catlin. 1973. "Passive Immunization of Calves against Experimentally Induced Enteric Colibacillosis by Vaccination of Dams." Am. J. Vet. Res. 34:29-33.

Yanaka, R., D. G. De Camargo, F. Bovino, W. A. Santos, M. R. Dócusse, B. S. Cavassano, e F. L. F. Feitosa. 2012. "Período de absorção intestinal de macromoléculas em cabritos recém-nascidos após a ingestão de colostro bovino." Pesq. Vet. Bras. 32(8):794-802. https://doi.org/10.1590/ S0100-736X2012000800020 